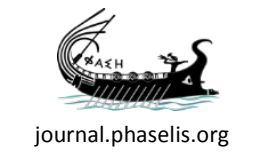

journal.phaselis.org

OPEN ACCESS JOURNALS

Atıf Düzeni Y. Mergen - A. R. Bilgin, “Phaselis Akropolis'indeki Doğu Roma İmparatorluğu Döne
mine Ait Değerlendirmeler". Phaselis II (2016) 123-132. DOI: 10.18367/Pha.16007

Geliş Tarihi: 20.04.2016 | Kabul Tarihi: 20.05.2016 | Online Yayın Tarihi: 22.06.2016

Editörya Phaselis Research Project www.phaselis.org

\section{Phaselis Akropolis'indeki Doğu Roma İmparatorluğu Dönemi Yerleşimine Ait Değerlendirmeler}

\author{
An Assessment of the East Roman Imperial Settlement on \\ the Acropolis of Phaselis
}

Yalçın MERGEN - Ali Rıza BíLGiN

PHASELIS: Disiplinlerarası Akdeniz Araştırmaları Dergisi'nde bulunan içeriklerin tümü kullanıcılara açık, serbestçe/ücretsiz "açık erişimli" bir dergidir. Kullanıcılar, yayıncıdan ve yazar(lar)dan izin almaksızın, dergideki makaleleri tam metin olarak okuyabilir, indirebilir, dağıtabilir, makalelerin çıktısını alabilir ve kaynak göstererek makalelere bağlantı verebilir.

PHASELIS: Disiplinlerarası Akdeniz Araştırmaları Dergisi uluslararası hakemli elektronik (online) bir dergi olup değerlendirme süreci biten makaleler derginin web sitesinde (journal.phaselis.org) yıl boyunca ilgili sayının içinde (Volume II: Ocak-Aralık 2016) yayımlanır. Aralık ayı sonunda ilgili yıla ait sayı tamamlanır.

Dergide yayımlanan eserlerin sorumluluğu yazarlarına aittir. 


\title{
Phaselis Akropolis'indeki Doğu Roma İmparatorluğu Dönemi Yerleşimine Ait Değerlendirmeler
}

\author{
An Assessment of the East Roman Imperial Settlement on the Acropolis of Phaselis
}

\author{
Yalçın MERGEN* Ali Rıza BíLGiN**
}

Öz: 1811 yııında F. Beaufort tarafından keşfedilen Phaselis antik kenti iki yüz yıldır belirli aralıklarla araştırma konusu olmuştur. Ancak, bu araştırmalar kentin daha çok Arkaik, Klasik, Hellenistik ve Roma İmparatorluğu dönemleri üzerinde yoğunlaşmıştır. 2012 yılında başlatılan multidisipliner araştırmalar kapsamında, 2013 yılında kentin Doğu Roma İmparatorluğu Dönemi'ne yönelik araştırmalar da yürütülmüştür. Yüzey araştırması olarak devam eden çalışmalar 2013 ve 2014 yıllarında Phaselis'in kent merkezi ve teritoryumunda yapılmıştır. 2015 yılında yapılan yüzey araştırması kentin akropolis'inde gerçekleştirilmiş ve Doğu Roma İmparatorluğu Dönemi kent arkeolojisine yönelik önemli veriler elde edilmiştir. Yapılan çalışmalar neticesinde Phaselis antik kenti Doğu Roma İmparatorluğu Dönemi yerleşiminin burada yoğunlaşıı̆ı anlaşılmıştır. Bu metnin amacı 2015 yılı çalışmalarında elde edilen verileri sunmak, bunları benzer örnekler ile karşılaştırarak Phaselis'in Doğu Roma İmparatorluğu Dönemi'ne ışık tutmaktır.

Anahtar Sözcükler: Lykia · Phaselis · Doğu Roma Imparatorluğu · Kent · Mimari · Ortaçağ

Abstract: Since its discovery in 1811 by F. Beaufort, the archaeology of the ancient city of Phaselis has been the subject of much research. However, the research that has taken place at Phaselis has been mainly focused upon its Archaic, Classic, Hellenistic and Roman Period remains. In 2013, the study of the Eastern Roman Empire (Byzantine) remains was included within the scope of multidisciplinary research program at Phaselis which began in 2012. In 2013 and 2014, the study of the Eastern Roman period remains, which continue as surveys, were conducted in Phaselis's city centre and its territorium. The survey that was conducted in 2015 was carried out on at the city's acropolis. This survey indicates the intensification of settlement in the Eastern Roman Period on the acropolis at Phaselis. Research in acropolis area provided significant evidence concerning this period at Phaselis. This paper presents the data acquired in the survey of 2015 year and enabling a better comprehension of the Eastern Roman Period at Phaselis.

Keywords: Lycia · Phaselis · Eastern Roman Empire · City · Architecture · Medieval

Phaselis Antik kentinde 2012 yılında başlatılan multidisipliner çalışmaların bir ayağını, kentin Doğu Roma İmparatorluğu Dönemi çalışmaları oluşturmaktadır. 2013 yııında başlanan ve "Doğu Roma imparatorluğu Dönemi arkeolojisi" başlığı altında yürütülen bu çalışmaların amacı, Phaselis'in bu dönemdeki kent dokusunu ve kentin antikiteden Hristiyanlık'a geçişte yaşadığı değişimlerin mimariye olan yansımalarını ortaya çıkarmaktır. Phaselis'te daha önce gerçekleştirilmiş olan çalışmaların olasılıkla imkân kısıtlılı̆ı ve kentin topografik durumu sebebiyle daha çok Hellenistik

* Öğr. Gör. Dr., Dokuz Eylül Üniversitesi, Güzel Sanatlar Fakültesi, Temel Eğitim Bölümü, Sanat Kuramları Anasanat Dalı, İzmir.ymergen68@gmail.com

** MA., Ege Üniversitesi, Sosyal Bilimler Enstitüsü, Sanat Tarihi Anabilim Dalı, İzmir. bilgin420@gmail.com 


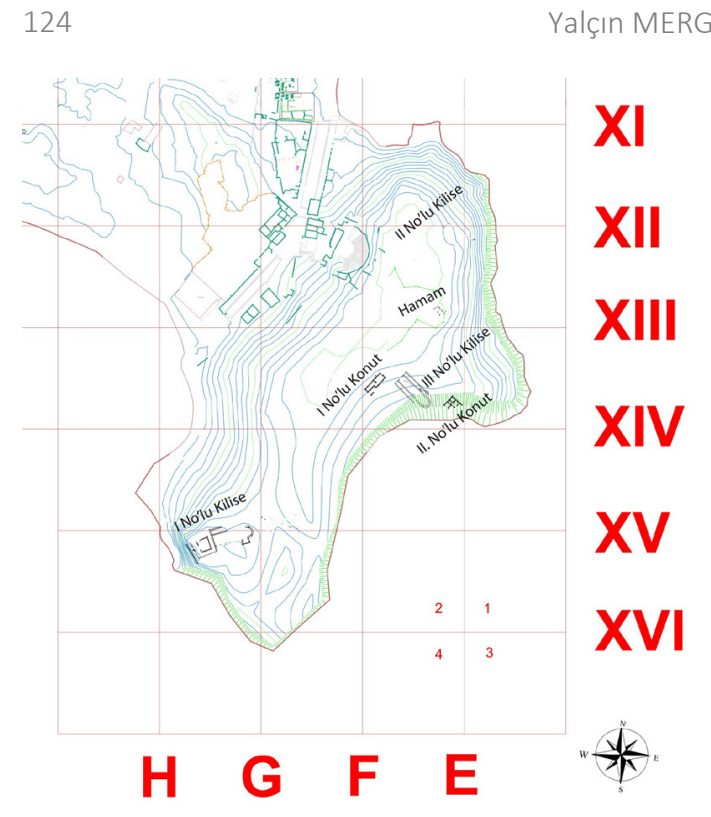

Fig. 1. Phaselis Antik Kenti Akropolis'i

ve Roma İmparatorluk dönemlerine yoğunlaşmış olması, 2013'ten bu yana yürütülen çalışmaları önemli kılmaktadır. 2013 ve 2014 yıllarında gerçekleştirilen arazi çalışmaları kent merkezi ve teritoryumunda yoğunlaşmıştır. 2014 yılında gerçekleştirilen çalışmalarda kent akropolis'inin Doğu Roma İmparatorluğu Dönemi'ne ilişkin önemli verilere ulaşılabileceği görülmüş ve bu bağlamda 2015 yılı çalışmaları akropolis üzerinde yoğunlaştırılmıştır ${ }^{1}$.

Yapılan araştırmalar sırasında bakanlık yönergesi gereği WGS84 koordinat sistemi kullanılmıştır. Phaselis antik kentine ait sayısal topografik kent planı ise ITRF96 koordinat sistemine göre düzenlenmiştir. Bu nedenle belirlenen buluntuların sayısal harita üzerinde görülen sektörlere yerleştirilebilmesi için WGS84 koordinat sistemine göre alınan lokasyon bilgilerinin ITRF96 koordinat sistemi değerlerine dönüştürülmesi işi ekibimiz tarafından gerçekleştirilmiştir. Yapılan çalışmalar, Phaselis antik kentinin sayısal topografik kent planında oluşturulan sektörlere sadık kalınarak gerçekleştirilmiştir.

F-XIV, XIII ve E-XIII, XII sektörlerinde yoğunlaştırılan çalışmalar neticesinde, iki kilise, iki konut ve bir küçük hamam tespit edilmiştir (Fig. 1). Bu yapıların birbirleriyle olan fiziki ilişkileri arazi koşullarının elverişsizliği sebebiyle net olarak saptanamamış olsa da yapılar konumları itibariyle, Phaselis'in Doğu Roma İmparatorluğu Dönemi akropolis yerleşkesine dair önemli ipuçları sunmaktadırlar.

\section{Numaralı Kilise}

II Numaralı Kilise'nin bulunduğu alan Phaselis'in Kuzey Liman'ına çok yakın bir mevkide akropolis'in kuzeydoğu yamacında ve deniz seviyesinden 25 metre yukarıda bulunmaktadır. 36.52390467 -27.55378801 koordinatlarında yer alan yapı Phaselis kenti sayısal topografik kent planında E- XIII3 sektörüne dâhildir.

Kilise günümüze plan şemasının anlaşılmasına olanak sağlayacak oranda görece sağlam şekilde ulaşmıştır. Batıda yer alan atrium'a ait çevre duvarları oldukça yıkık durumdadır. Söz konusu yıkıntıya ait moloz nedeniyle atrium içinde olması muhtemel yapısal detaylar görülememektedir. Bununla beraber atrium'a güney ve kuzey duvarlarda yer alan kapı açıklıklarından girildiği anlaşımaktadır.

Narteksi olmayan yapının atrium'undan naos'a üç giriş açıklığı ile doğrudan geçiş sağlanmıştır. Ana ve güney nefe açılan kapılar günümüze sağlam ulaşmıştır. Yapının ana aksında bulunan ve tahminen apsis ile aynı genişliğe sahip olan ana nefe açılan kapının, ana nefi vurgulamak amacıyla yan neflere açılan kapılardan daha yüksek ve geniş olarak düzenlendiği anlaşılmaktadır (Fig. 2). Yüzeyde yıkıntı molozunun izin verdiği ölçüde izlenebilen stilobat ve stilobat üzerinde in situ durumda yer alan taşıyıcılara dayanarak, yapının üç nefli Hellenistik bazilikal plan şemasına sahip olduğu anlaşılmaktadır. Bu plân tipi Lykia Bölgesi erken dönem dini mimarisinde sıkça rastlanan

12014 yılı çalışmaları için bk. Mergen 2015. 
bir plan tipidir ${ }^{2}$.

Ana mekânı sınırlayan duvarlardan yalnızca batı ve güneydekiler günümüze sağlam ulaşabilmiştir. Kuzey nefe ve apsis'e ait duvarlar heyelân nedeniyle tamamen tahrip olmuştur. Bu nedenle ve özellikle yapının apsis'inin plân ve yapısal özelliklerine dair herhangi bir öneride bulunmak mümkün değildir. Ancak yapının güney nef duvarının günümüze daha sağlam ulaşmış olması sayesinde kilisenin pencere açıkıklarına sahip olduğu anlaşılmaktadır. Stilobat üzerindeki taşıyıcı sisteme ait kalıntılara dayalı olarak, örtü sisteminin kare kesitli payeler ile desteklendiği

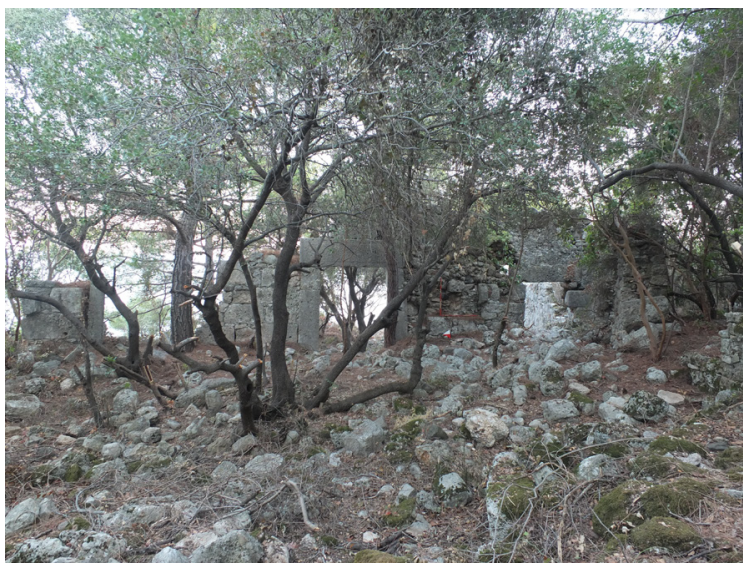

Fig. 2. II Numaralı Kilise Naos Giriş Düzenlemesi (Batıdan Doğuya Bakış) anlaşılmaktadır.

Yapıda kullanılan inşa malzemesi kabayonu kesmetaş, moloztaş ve devşirme kesmetaştır. Bağlayıcı malzeme olarak kireç harcı kullanıldığı görülmektedir. Ana nefe giriş kapısında ve güney nef duvarı üzerindeki izlerden yapının zengin bir süsleme programına sahip olduğu anlaşılmaktadır. Ancak bu izler stil, kritik tespiti ve ikonografik çözümleme için yeterli veri sunmamaktadır (Fig. 3). Yapının iç dekorasyonuna ait bir başka buluntu ise mozaik döşemesidir. Dalgalı şeritlerin oluşturduğu daire formlarından meydana gelmiş, çeşitli renklerde taşların kullanıldığı mozaik MS V-VI. yüzyıllara tarihlendirilebilir ${ }^{3}$ (Fig. 4).

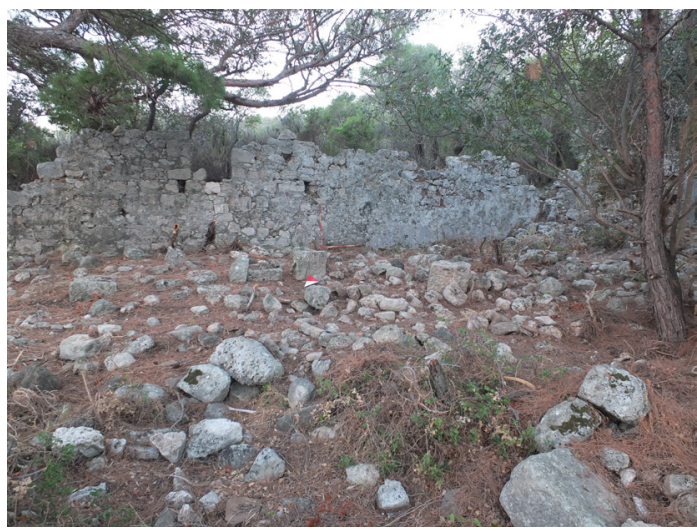

Fig. 3. Il Numaralı Kilise, Güney Nef Duvarı (Kuzeyden)

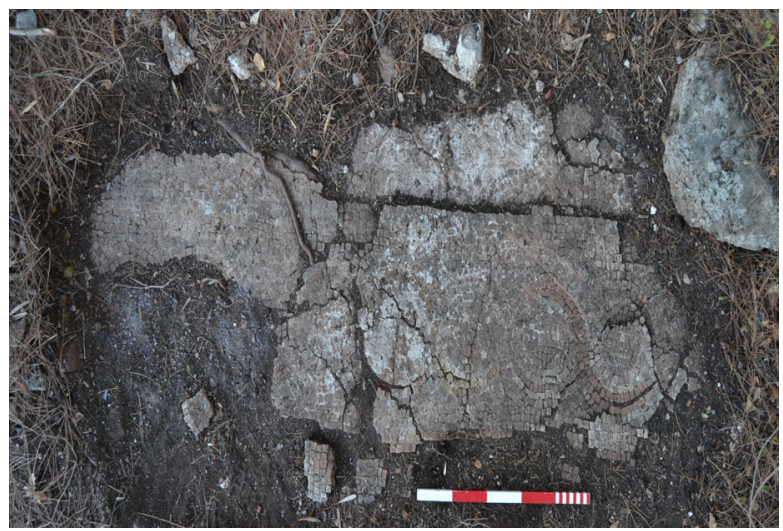

Fig. 4. II Numaralı Kilise Mozaik

Yapılan çalışmalarda II numaralı kiliseye ait bir başka buluntu grubu ise mimari plastik parçalardır. Elde edilen parçaların tür, bulundukları yer, boyut ve benzer örneklerden yola çıkarak, işlevlerinin litürjik mimari plastik olduğu anlaşılmaktadır ${ }^{4}$. Levha, baluster, templon arşitravı gibi parçalar yüzeyde bulundukları için günümüze oldukça tahrip olmuş bir şekilde ulaşmışlardır (Fig. 5).

II Numaralı Kilise plan özellikleri nedeniyle, Lykia Bölgesi'nde MS V. ve VI. yüzyılara tarihlendirilen örneklerle örtüşmektedir. Gemiler Ada I, II, III ve IV numaralı kiliseler, Ölüdeniz Kumsal

\section{Harrison 1963, 148.}

Motif örneği için bk. Balmelle et al. 1985, pl. 118 b. Benzer bir örnek için ayrıca bk. Tok et al. 2013, 89.

Benzer örnek için bk. Mathews 1971, levha 15, 16, 89. Doğan 2004, res. 8. 
Bazilikası, Olympos 1 Numaralı Kilise ${ }^{5}$, Ölüdeniz Lagün Bazilikası, Besta Koyu Kilisesi ${ }^{6}$, Ksanthos Akropolis Kilisesi', Ksanthos Büyük Bazilika ${ }^{8}$ ve Kydna Bazilikası'nın ilk evresi ${ }^{9}$ gibi örnekler Lykia Bölgesi'nde görülen üç nefli Hellenistik bazilikal plan tipine sahip yapılardandır.

\section{Hamam}

Phaselis kent planında E-XIII,2 sektöründe yer alan yapı $36.52314480-27.5533879$

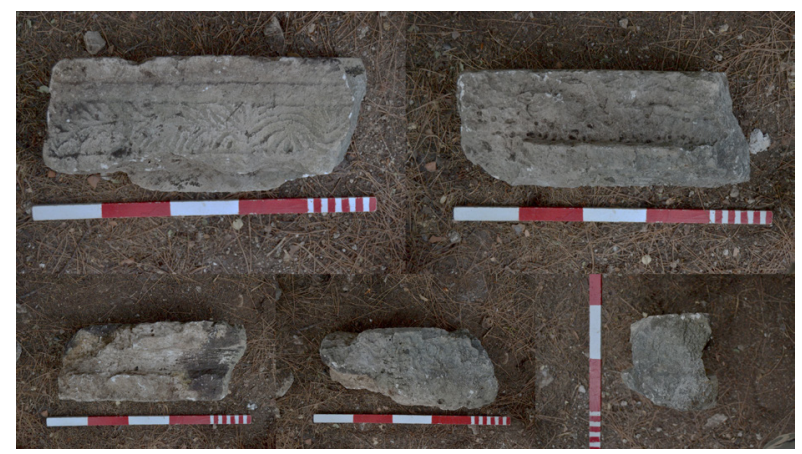

Fig. 5. II Numaralı Kilise Baluster koordinatlarındadır. Hamam tek başına ve kamusal hizmet veremeyecek kadar küçük boyutlardadır 4,35 × 9,95 m ölçülerindeki yapının yüzey araştırması olanaklarının elverdiği koşullar çerçevesinde bir başka yapı ve/veya mekânla ilişkisi saptanamamıştır. Geç Antik ve Erken Hristiyanlık dönemlerinde Suriye ve Filistin bölgelerinde bu tarz küçük hamamların inşa edildiği bilinmektedir $^{10}$. Giriş mekânı da dâhil olmak üzere bir soğukluk ve sıcaklıktan oluşan eş-

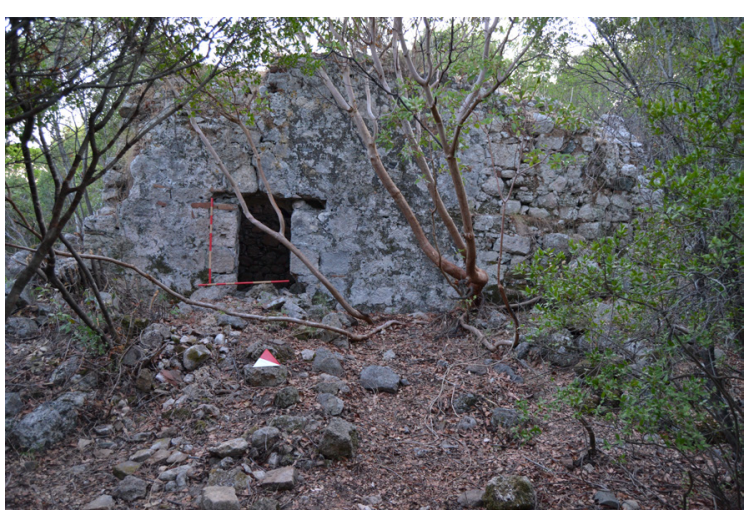

Fig. 6. Hamam (Dışarıdan)

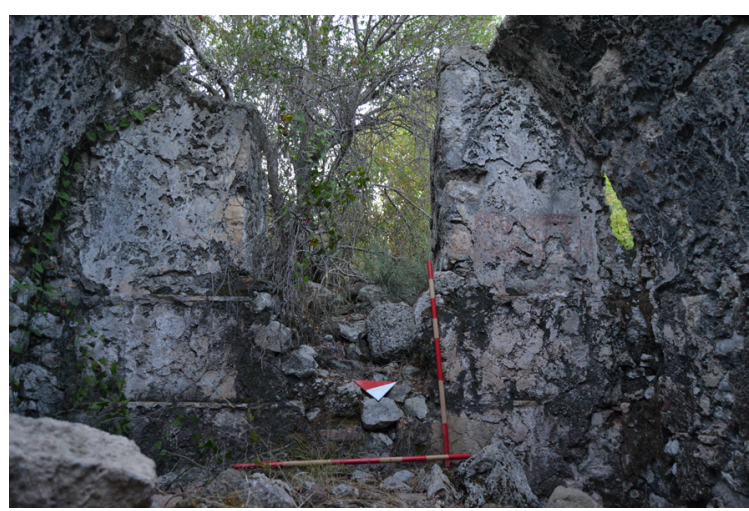

Fig. 7. Hamam Sıcaklık Bölümü birimli bir yapıdır (Fig. 6-7). Örtü sistemi tonoz olan yapının elde edilen bulgular sonucunda yerden ve duvardan Isıtma sistemine sahip olduğu anlaşıımaktadır. Yapının sıcaklık bölümünde kuzey ve güney duvarları üzerine karşılıklı olarak nişler yerleştirilmiştir. Kuzey duvar üzerindeki absidal planlı ve çeyrek kubbeli niş dışarıya doğru çıkıntı yapmaktadır. Yapıdaki en büyük tahribatlar hangi tarihlerde yapıldığı bilinmeyen kaçak kazılar nedeniyle oluşmuştur. Sıcaklık bölümünde hipokaust sistemine dair payeler ve kaplamalar bu bilinçsiz müdahaleler nedeniyle kısmen bozulmuştur.

Hamamda ayrıca sıcaklık bölümü doğu duvarı üzerinde kırmızı boya ile yapılmış tabula ansata üzerine beyaz boyalı harfler ile yazılmış bir yazıt tespit edilmiştir (Fig. 7). Araştırma ekibinin epigraflarınca incelenen yapıdaki yazıt üzerindeki harfler tahribattan dolayı net olarak okunamamıştır. İleride gerçekleştirilecek daha kapsamlı bir incelemenin daha net sonuçlar vereceği kanısındayız.

\footnotetext{
Olympos 1 Numaralı Kilise; Gökalp - Yıldırım 2010, 367-387.

Kazuno 1995, 407-419.

Canbilen et al. 1996, 201-229.

Sodini 1980, 119-148.

Adam 1977, 66-69.

10 Yegül 1996, 326, 329.
} 


\section{Numaralı Kilise}

Akropolis üzerinde 2015 çalışmaları sırasında tespit edilen bir başka kilise ise 36.52240014 27.55331841 koordinatlarında, E- XIV sektöründe yer alan III numaralı yapıdır.

Yapının batısında yer alması muhetemel atrium ve/veya narteks birimleri moloz yığınları ve yoğun bitki örtüsü nedeniyle görülememektedir. Ancak moloz yığının kalınlığı ve yer yer görülebilen sütun ve sütun başlığı parçaları yapının batısında özenli ve anıtsal bir mimari düzenleme olduğuna işaret etmektedir. Kilisenin batısındaki mimari birim ya da birimlerin niteliği ancak ileride yapılacak olan arkeolojik kazılar neticesinde anlaşılabilecektir. Yaklaşık doğu-batı uzantılı olan yapının ana mekânı 40,00 x 16,80 metre ölçülerindedir (Fig. 8). III numaralı kilise boyutları itibariyle, Phaselis antik kenti akropolis'inde tespiti yapılan diğer kiliselerle birlikte (I Numaralı ${ }^{11}$, II Numaralı) Lykia Bölgesi'nde görülen büyük bazilikal planlı kiliseler arasında değerlendirilebi$\operatorname{lir}^{12}$. Bu veriler, Doğu Roma İmparatorluğu Dönemi Phaselis'inin akropolis'i üzerinde yoğun bir nüfus barındırdığını düşündürmektedir.
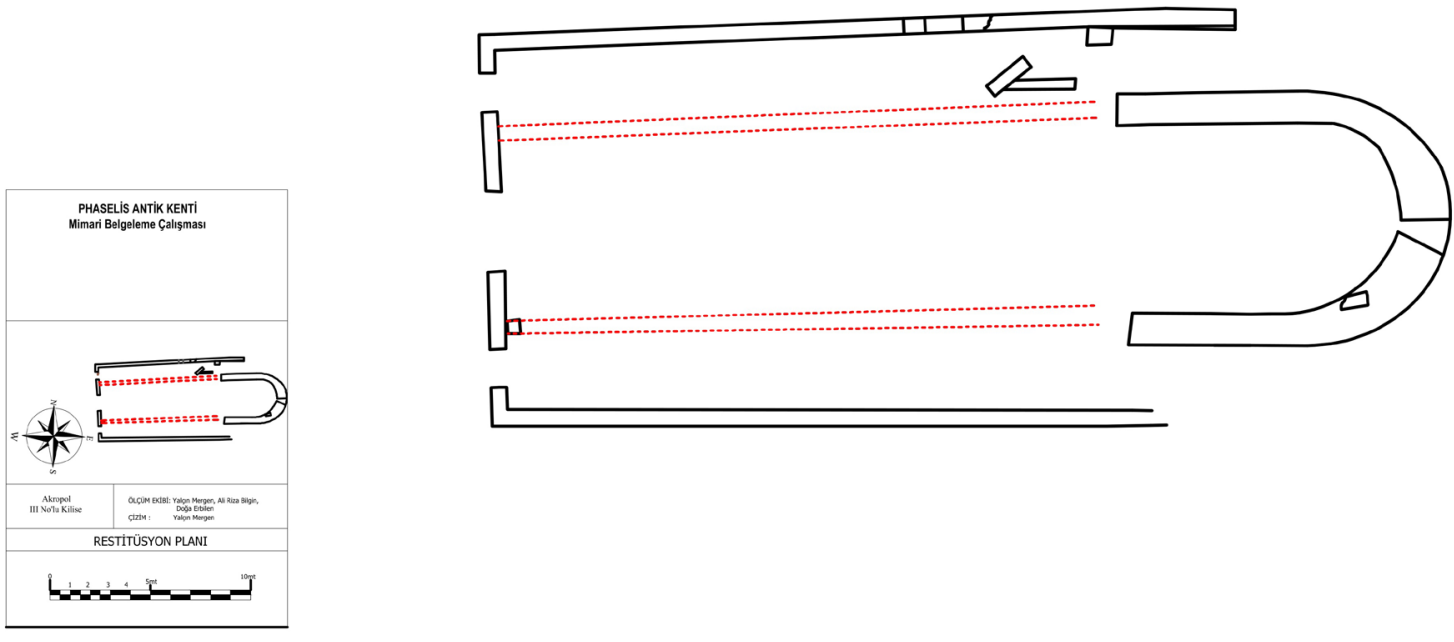

Fig. 8. III Numaralı Kilise Planı

Kalıntılardan kiliseye batıda yer alan üç kapı açıklığı ile girildiği anlaşılmaktadır. Bunlardan, ana nefe girişi sağlayanın daha geniş olduğu yine kapı sövelerine ait olan kalıntılardan yola çıkılarak söylenebilir. Naos'ta yer yer görülebilen stilobat izleri ve yıkılmış sütun dizileri yapının üç nefli Hellenistik bazilikal plan şemasında inşa edildiğini kanıtlamaktadır (Fig. 8-9). Ayrıca naos’ta hem ana hem de yan neflerde tespit edilen ve yıkım sonrasında oldukları yerde kalan devşirme sütun ve sütun kaideleri, yapının taşıyıcı sisteminin sütun olduğunu işaret etmektedir.

Bununla beraber yapı mimari açıdan birtakım ilginç özellikler barındırmaktadır. Özellikle apsis duvarlarının kalınlığı (Fig. 10), apsis'in doğu batı doğrultusunda çok derin olması Lykia Bölgesi Hristiyan dini mimarîsi örneklerinde görülen özellikler değildir. Apsis'in bu özellikleri Lykia dışı örnekleri gündeme getirmektedir. Kilikya Bölgesi dini mimarîsi örnekleri arasında uzatılmış at

112014 yılı çalışmalarında tespiti yapılan kilise hakkında bk. Mergen 2015.

12 Lykia Bölgesi'nde görülen büyük boyutlardaki bazilikal planlı kiliseler şunlardır: Patara, Büyük Kilise 43,50 x 33,00 m; Ksanthos, Doğu Kilise 39,70 x 30,00 m; Limyra, Piskoposluk Kilisesi 40,00 x 25,00 m; Demre, Aziz Nikolaos Kilisesi 40 × 25 m (ilk yapım evresi); İşler 2009, 254. 


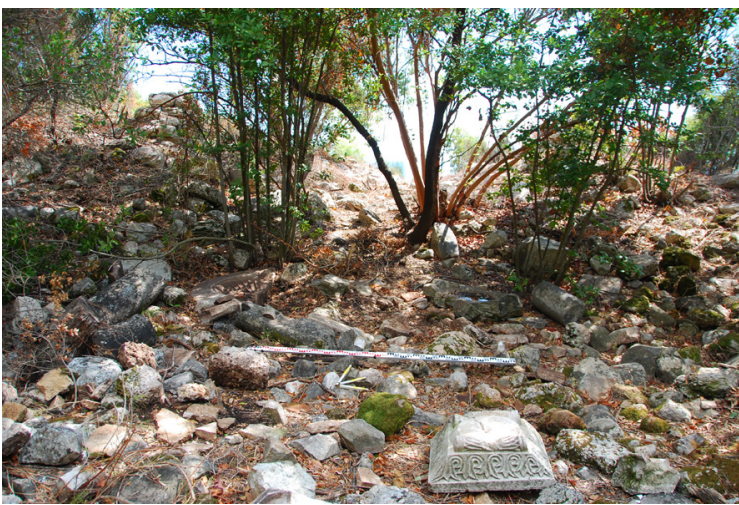

Fig. 9. III Numaralı Kilise Bema. Plastik Eserler ve Devşirme Sütun Parçaları (Doğuya Bakış)

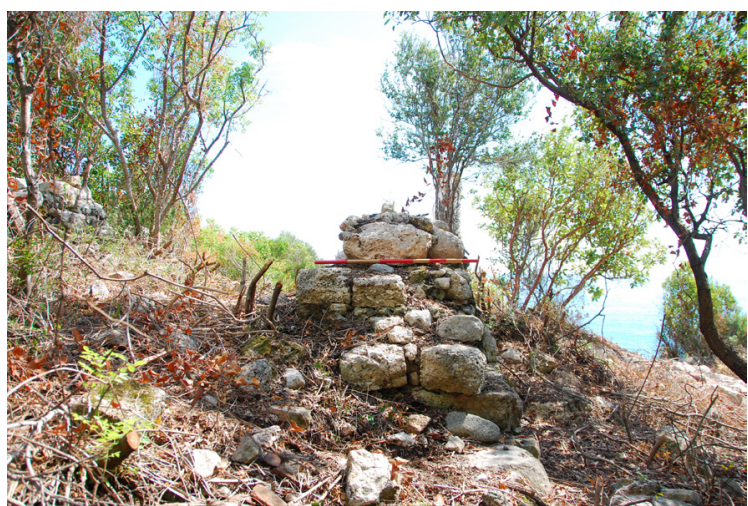

Fig. 10. III Numaralı Kilise Apsis Duvar Başlangıdı (Doğuya Bakış)

nalı plânlı apsislerin bulunduğu bilinmektedir ${ }^{13}$. Bu nedenle III Numaralı Kilise Lykia Bölgesi'nde bilinen ilk örnek olduğundan önem taşımaktadır.

Özellikle apsis duvarının kuzey ve güney duvarlarla ilişkili olmasına rağmen doğuya doğru daha da kalınlaştırılarak düzenlenmiş olması, yapıdaki örtü sistemine ait statik sorunları aşma çabasını işaret etmektedir. Sorunların çözülmesinde uygulanan yöntemin iptidai olduğu bölgedeki benzer örneklerle kıyaslandığında anlaşılmaktadır. Bu veriler doğrultusunda inşa faaliyetini yerel bir atölyenin gerçekleştirdiği düşünülebilir.

Söz konusu duvarların yapının cephe duvarlarına göre çok daha geniş düzenlenmiş olması ana mekân, apsis önü ve apsis'in örtü sistemlerinin farklı tasarlandığını düşündürmektedir. Naos'un örtü sisteminin ahşap olduğu açıktır. Yukarıda değinilen özellikler nedeniyle de apsis önünde yer alan mekânın tonoz, apsis'in ise yarım kubbeyle örtüldüğü varsayılabilir.

Kuzey apsis duvarının naos'ta sonlandığı kısımda görülen duvar izleri ve kuzey nefte görülen devşirme arşitrav ve söve blokları burada bir kapı olabileceğini düşündürmektedir. Bu uygulamaya benzer örnekleri Lykia Bölgesi'nde görmek mümkündür. Asarcık Doğu Kilise, Andriake A, B, $C$ ve E kiliseleri, Ksanthos Doğu, Sura Vadi, Güceyman Tepesi, Danabaşın Zeytinlik Mevkii kiliseleri bu düzenlemeye sahip yapılardır ${ }^{14}$. Bu örneklerin dışında Lykia kıyı kentlerinden olan Olympos antik kentinde, kuzey kent yapı ada no I içerisindeki kilisede de kuzey nef duvarı üzerinde giriş açıklığı mevcuttur ${ }^{15}$. Bölgede bulunan diğer örnekler bu önermelerin doğruluğunu desteklese de kesinliğe kavuşmaları ancak yapılacak bir arkeolojik kazı ile mümkün olacaktır.

Yapının güney nef duvarı temel seviyesine kadar yıkık olduğundan bu duvarın yapısal özellikleri hakkında bir şey söylemek mümkün değildir. Ancak kuzey nef duvarı güneye nazaran daha sağlam durumdadır (Fig. 11). Bu duvarın doğu kısmındaki pencere açıklıklarının izleri görülmektedir. Buradan yola çıkarak yapının güney nef duvarı üzerinde de pencere açıklıkları bulunduğu söylenebilir. Ayrıca apsis'in ana aksında ve apsis duvarının kalınlığının arttığı bölümde birer mazgal pencere olduğu yapısal izlerden anlaşılmaktadır.

Yapıda taşıyıcı olarak kullanılan devşirme sütunlar arasında olması beklenen yatay taşıyıcı

13 Hill 1996, fig. 40, 58. Kilikya Bölgesi'nde yer alan Karlık Bazilikası ve Uzunca Burç Stephanos kiliselerinin apsis'leri uzatılmış at nalı planına sahip olmakla beraber, boyut ve duvar kalınlıkları açısından III Numaralı kilise ile farklııklar göstermektedir.

14 işler 2009, 241.

15 Mergen 2011, 331. 
unsurlara dair bir ize henüz rastlanmamıştır. Bunun yanı sıra gördükleri tahribat nedeniyle üslupları tam olarak anlaşılamayan sütun başlı̆ı parçaları, saptanan mimari plastik eserler arasındadır. Phaselis antik kentinde günümüze yakın dönemlerde, yaşandığı bilinen yangınların yüzeyde bulunan bu malzemelere ağır hasarlar verdiği görülmektedir. Fragmanlar halinde yüzeyde bulunan başlıklar haricinde ana nef üzerinde sağlam vaziyette bitkisel bezemeli bir lon-impost sütun başlığı mevcuttur. Ion-impost sütun başlıklarının

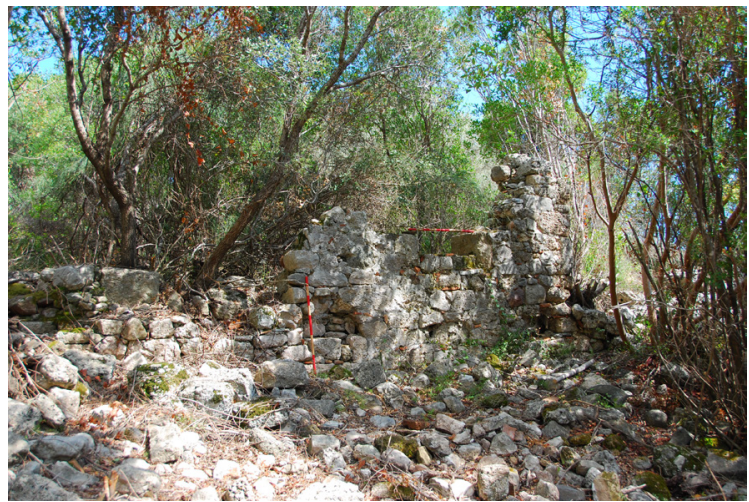

Fig. 11. Kuzey Nef Duvarı (Güneybatıdan)

Anadolu'da ve Konstantinopolis'te lustinianus Dönemi'nde örnekleri görülmektedir ${ }^{16}$. İskenderiye Müzesi'nde MS V. yüzyılın ilk çeyreğine tarihlenen ve yerel üretim olduğu düşünülen iki Ionimpost sütun başlığı bu tür mimari plastik eserlerin bilinen en erken örneklerindendir ${ }^{17}$. III. Numaralı Kilise içerisinde bulunan başlığın yerel üretim olma olasılığının yanı sıra Phaselis'in, Mısır ile olan ticari ilişkileri göz önüne alındığında, İskenderiye'den taş eser ithal edilmiş olabileceği uzak olmakla birlikte intimal dâhilindedir. Sütun başlıkları dışında yapının bemasına yakın bölümde merkezinde madalyon içinde haç bulunan istiridye kabuğu bezemeli bir ambon ya da kiborion tepeliği, kiliseye ait mimari plastik eserler arasındadır (Fig. 9).

III Numaralı Kilise apsis bölümü dışında plan özellikleri açısından Lykia Bölgesi'nin MS V. ve VI. yüzyıllar arası dini mimari plan şemalarına ve malzeme-teknik özelliklerine uyum göstermektedir. Örneğin: Andriake A, B ve C kiliseleri ${ }^{18}$, Arneai B ve Kök Burnu kiliseleri ${ }^{19}$ Gemiler Ada, Ölüdeniz Kumsal Bazilikası, Ölüdeniz Lagün Bazilikası, Besta Koyu Kilisesi ${ }^{20}$, Ksanthos Akropolis Kilisesi ${ }^{21}$, Ksanthos Büyük Bazilika ${ }^{22}$ ve Kydna Bazilikası'nın ilk evresi ${ }^{23}$ gibi yapılar nef sayıları ve yapısal proporsiyonlar açısından III numaralı kilise ile benzerlikler göstermektedir. Ayrıca elde edilen mimari plastik buluntular da yapının bu tarihlerde inşa edilmiş olabileceğini işaret etmektedir. Ancak yapının hem apsis tipi ve ölçüleri hem de kuzey ve güneyde doğuya doğru uzanan dehlizler yapıyı söz konusu örneklerden ayırmaktadır.

\section{Numaralı Konut}

Akropolis yarımadası üzerinde 36.52246245 - 27.55290140 koordinatlarında, F-XIV,2 sektöründe yer alan yapı farklı boyutlarda birçok mekana sahiptir. $22 \times 7,50$ metrelik bir alan üzerinde konumlanmıştır (Fig. 12). Bir düzlük üzerinde yer alan yapının duvarları batıda ve kısmen kuzeyde temel seviyesinde izlenmektedir. Batısındaki duvarlardan bir odanın birden fazla kata sahip olduğu anlaşıımaktadır. Yapının en önemli özelliği Phaselis'in Erken Doğu Roma İmparatorluğu yerleşimine dair önemli veriler sunabilecek olmasıdır. Yapının kuzey bölümünde ve alt kotta izlenebilen; işçilik, boyut ve teknik yönlerinden incelendiğinde daha erken dönemlere ait olduğu

\footnotetext{
16 Konstantinopolis örnekleri için bk. Matthews 1971, levha 18 ve 55.

17 Yegül 1974, 267.

18 Detaylı bilgi için bk. Tekinalp 2000.

19 Harrison 1963, 139 fig 15, 141 fig 17.

20 Kazuno 1995, 407-419.

21 Canbilen et al. 1996, 201-229.

22 Sodini 1980, 119-148.

23 Adam 1977, 66-69.
} 

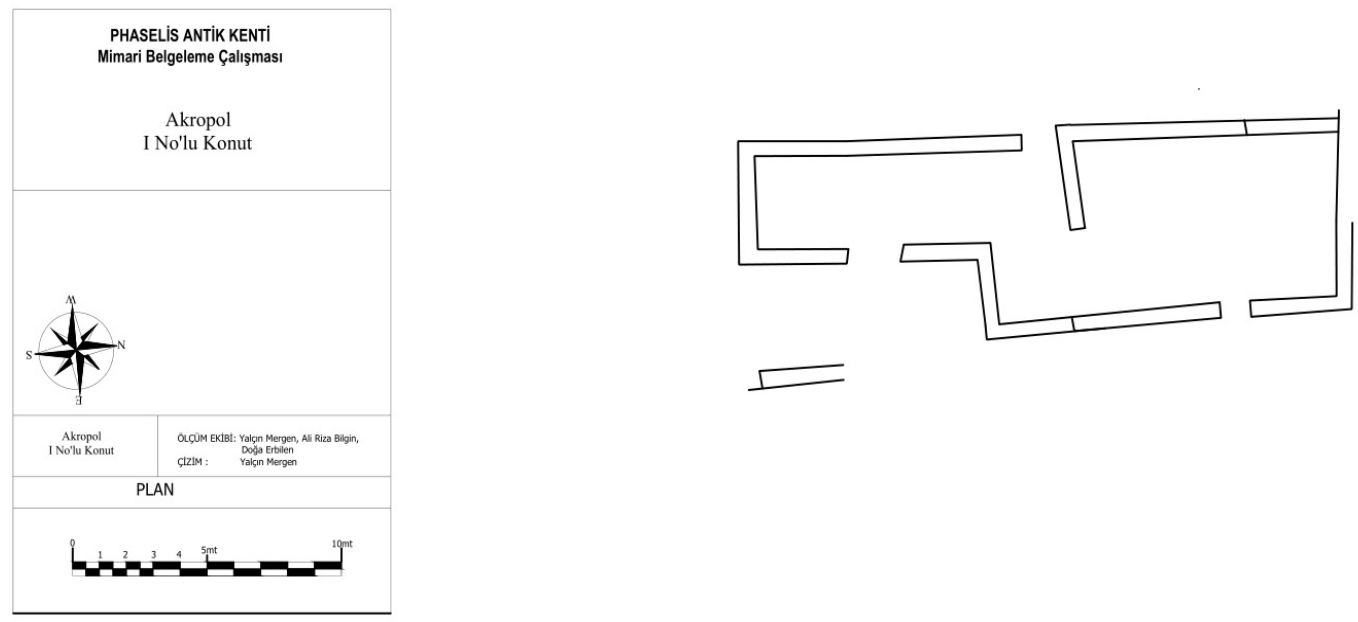

Fig. 12. I Numaralı Konut Planı

anlaşılan duvarların üzerine Hristiyanlık Dönemi yapısına ait duvarlar yerleştirilmiş, erken dönem duvarları temel görevi görmüştür.

\section{Numaralı Konut}

E-XIV,2 sektöründe yer alan yapı, 36.52235780 - 27.55381986 koordinatlarındadır. III numaralı kilisenin yaklaşık 10 m kuzeydoğusunda yer almaktadır. Günümüzdeki durumuyla konut 13,45 x 13,50 m ölçülerinde bir alanı kaplamaktadır. Konut günümüze oldukça sağlam ulaşmış olmasına rağmen, bulunduğu konumdan kaynaklı tahribat da oluşmuştur. 19 m yüksekliğindeki bir uçurumun hemen yanında bulunan yapının doğusundaki mekânların bazıları heyelan ve erezyon gibi sebeplerden dolayı yok olmuştur. Yapının sağlam kısımları plan özelliği ve yapısal özellikler açısından anlaşılır veriler sunmaktadır. Mekân topluluğuna, batıda yer alan kemerli ve anıtsal bir kapıdan girilmektedir (Fig. 13). Bu giriş aksında devam eden bir koridor etrafına beş adet mekân, sıralı ve simetrik olarak yerleştirilmiştir. Mekânların birden fazla kat düzenlemesine sahip olduğu yapısal izlerden anlaşılmaktadır. İnşa malzemesi kabayonu kesmetaş ve moloztaş, bağlayıcı mal-

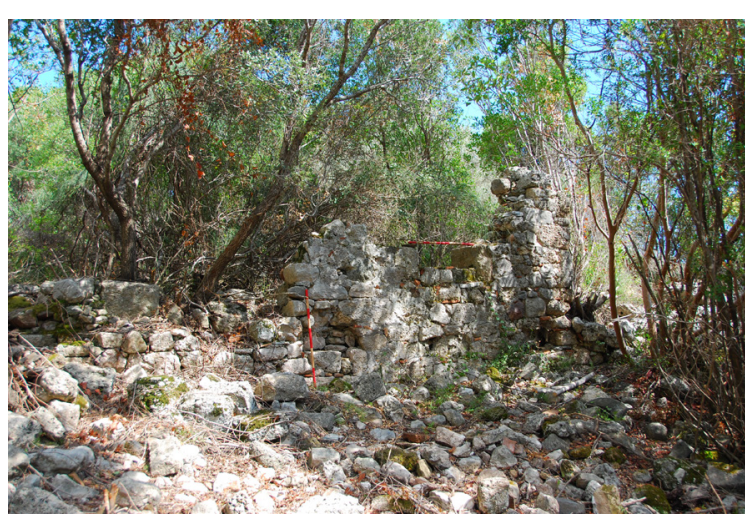

Fig. 13. II Numaralı Konut Giriş Kapısı ve Iç Mekân zeme ise kireç harcıdır. Yüzeydeki veriler doğrultusunda mekân topluluğunun bir avluya sahip olabileceği düşünülmektedir. Plân düzenlemesi, malzeme ve yapım tekniği açısından Olympos antik kentinde tespiti yapılan konutlarla büyük benzerlikler göstermektedir. Özellikle kemerli girişe sahip, mekânlara dağılımı sağlayan koridor düzenlemesi, Olympos antik kentindeki "Giriş Kompleksi" olarak adlandırılan yapıda da görülmekte$\operatorname{dir}^{24}$.

\section{Değerlendirme}

Phaselis antik kenti 2015 yılı Doğu Roma İmparatorluğu Dönemi çalışmaları, 2014 yılı çalışmaları

24 Mergen 2011, 340. 
ile uyumlu sonuçlar ortaya koymuştur. 2014 yılı çalışmaları neticesinde kentin Doğu Roma İmparatorluğu Dönemi -Ortaçağ- yerleşiminin akropolis üzerinde yoğunlaştığı öngörülmüştür ve bu yıl gerçekleştirilen çalışmalarda elde edilen bulgular da bu öngörüyü destekler niteliktedir. Yapılan çalışmalarda iki kilise, iki konut ve bir hamam ortaya çıkarılmıştır. 2014 yılında keşfedilen I Numaralı Kilise de dâhil edildiğinde Phaselis akropolis'inde, Doğu Roma İmparatorluğu Dönemi'ne ait mimari eserler üçü dinî, ikisi sivil, biri kamusal ${ }^{25}$ olmak üzere toplamda altıdır. Yapıların, bulundukları konumlar değerlendirildiğinde Ortaçağ Phaselis'inin akropolis'i üzerine yayıldığı söylenebilir. Yapılan yüzey araştırması, 2016 yılı çalışmalarıyla daha da detaylandırılacak olan Phaselis'in Ortaçağ kent planına bir altlık sunmuştur.

25 Hamam yapısı kamu binası olarak değerlendirilmekle birlikte, bilinen boyutları itibariyle şahsî kullanıma ait bir yapı da olabilir. Bu belirsizlik ileride gerçekleştirilecek çalışmalar ile kesinlik kazanacaktır. 
Adam 1977

Balmelle et al. 1985

Canbilen et al. 1996

Doğan 2004

Gökalp - Yıldırım 2010

Harrison 1963

Hill 1996

Işler 2009

Kazuno 1995

Mathews 1971

Mergen 2011

Mergen 2015

Sodini 1980

Tekinalp 2000

Tok et al. 2013

Yegül 1974

Yegül 1996

\section{BIBLIYOGRAFYA}

J. P. Adam, "La Basilique Byzantine De Kydna De Lycie Notes Descriptives Et Restitutions". Revue Archéologique 1 (1977) 53-78.

C. Balmelle, M. Blanchard-Lemee, J. Christophe, J.-P. Darmon, A.-M. Guimier-Sorbets, H. Lavagne, R. Prudhomme - H. Stern, Le Décor Géométrique de la Mosaïque Romaine. I Répertoire Graphique et Descriptif des Compositions Linéaires et Isotropes. Paris 1985.

H. Canbilen, P. Lebouteiller - J Sodini, " La Basilique de L'Acropole Haute de Xanthos". Anatolia Antiqua IV (1996) 201-229.

Sema Doğan, "Alanya Müzesi'ndeki Bizans Dönemi Taş Eserleri". Araştırma Sonuçları Toplantısı XXII/2 (2004) 71-77.

Z. D. Gökalp - Ş. Yıldırım, "Lykia Olympos'unda Bir Restitüsyon Denemesi". Adalya XIII (2010) 367-387.

R. M. Harrison, "Churches and Chapels of Central Lycia". Anatolian Studies 13 (1963) 117-151.

Stephen Hill, The Early Byzantine Churches of Cilicia and Isuria. Aldershot 1996.

B. İşler, Likya Bölgesi'nde Karabel Asarcık'taki Erken Bizans Dönemi Yerleşimi. Yayımlanmamış Doktora Tezi, Hacettepe Üniversitesi. Ankara 2009.

A. Kazuno, "Survey of The Early Byzantine Sites in Ölüdeniz-Gemilerada Area". AST XII (1995) 407-419.

T. F. Mathews, Early Churches of Constantinople Architecture and Liturgy. Pennsylvania 1971.

Y. Mergen, Olympos Antik kenti'nin Orta Çağ Dönemi Dokusu ve Likya Bölgesi Açısından Önemi. Yayımlanmamış Doktora Tezi, Ege Üniversitesi. İzmir 2009.

Y. Mergen, "2014 Yılı Çalışmaları Işığında Phaselis Antik kenti'nin Geç Antik ve Ortaçağ Mimarisi ile Kentsel Yapısı". Phaselis I (2015) 273-285. DOI: 10.18367/Pha.15014

J. P. Sodini, "Une Iconastase Byzantine a Xanthos". Actes du Colloque sur la Lycie Antiqua 27 (1980) 119-148.

V. M. Tekinalp, Geç Antik Dönem Sonrasında ve Ortaçağ'da (M.S. 4. - 14. yy.) Andriake Kenti. Yayımlanmamış Doktora Tezi, Hacettepe Üniversitesi. Ankara 2000.

E. Tok, A. Talaman - M. Atıcı, "Nymphaion (Kemalpaşa) Yakınlarında Bir Roma Villasının Mozaikleri: Eski Ahit Öyküleri Üstüne Bir Yorum". Journal of Mosaic Research V/6 (2013) 59-105.

Fikret K. Yegül, "Early Byzantine Capitals from Sardis. A Study on the Ionic Impost Type". Dumbarton Oaks Papers 28 (1974) 265-274.

Fikret Yegül, Baths and Bathing in Classical Antiquity. New York 2006. 